Rev. bras. paleontol. 15(2):141-152, Maio/Agosto 2012

(C) 2012 by the Sociedade Brasileira de Paleontologia

doi:10.4072/rbp.2012.2.03

\title{
NOVA ESPÉCIE DE SPHENOPHYTA NO EOPERMIANO DO RIO GRANDE DO SUL (GRUPO ITARARÉ, BACIA DO PARANÁ)
}

\author{
GUILHERME ARSEGO ROESLER \& ROBERTO IANNUZZI \\ Departamento de Paleontologia e Estratigrafia, Instituto de Geociências, UFRGS, Cx.P. 15001, \\ 91.509-900, Porto Alegre, RS. guilherme.paleonto@gmail.com, roberto.iannuzzi@ufrgs.br
}

\begin{abstract}
NEW SPECIE OF SPHENOPHYTA IN EARLY PERMIAN OF RIO GRANDE DO SUL (ITARARÉ GROUP, PARANÁ BASIN). A new species of Sphenophyta from Lower Permian strata of the Paraná Basin is recorded herein, which is characterized by its long free leaflets and shows similarities with forms, assigned to morphogenera Phyllopitys Zalessky and Annulina Neuburg, typical taxa from "Angarian Flora". The specimens come from two different sections, both belonging to the Itararé Group (Supergroup Tubarão), situated at the Morro do Papaléo outcrop, in the municipality of Mariana Pimentel, Rio Grande do Sul State, southern Brazil. Some of the study specimens were previously classified as Phyllotheca indica Bunbury. Nevertheless a more accurate analysis indicated that specimens are not really belonging to this morphospecies. New collections and comparisons with other already described specimens led to the proposition of a new species of the genus Phyllotheca. Despite the similarities with Phyllopitys, difficulties in the characterization of this morphogenus and the absence of fertile portions in this material did not permit to establish a real botanic affinity between this form and Angarian ones. Anyway, one cannot discard the possibility that apparent similarity amongst vegetative portions just represents a phenomenon of homoplasy, as already assigned to other similar floristic elements found in distinct Paleozoic floral realms.
\end{abstract}

Key words: Sphenophyta, Morro do Papaléo outcrop, Itararé Group, Rio Grande do Sul State, Early Permian.

\begin{abstract}
RESUMO - Apresenta-se aqui uma nova morfoespécie de esfenófita para o Eopermiano da bacia do Paraná, a qual se caracteriza por possuir longos folíolos livres e alguma semelhança com formas assinaladas aos morfogêneros Phyllopitys Zalessky e Annulina Neuburg, táxons típicos da "Flora Angárica". Os espécimes provêm de duas seções distintas, pertencentes ao topo do Grupo Itararé (Supergrupo Tubarão), que afloram no Morro do Papaléo, município de Mariana Pimentel, Rio Grande do Sul. Alguns dos espécimes estudados foram previamente classificados em Phyllotheca indica Bunbury, porém, uma análise detalhada indicou que eles não pertenciam a esta morfoespécie. Novas coletas e comparações com amostras já descritas possibilitaram incluir estes espécimes numa nova espécie do morfogênero Phyllotheca. Apesar da similaridade com Phyllopitys, problemas na caracterização deste morfogênero e a ausência de ramos férteis no material estudado, não permitiram estabelecer uma real afinidade botânica entre esta forma e as angáricas já conhecidas. De qualquer modo, não se descarta a possibilidade de que a aparente semelhança entre as porções vegetativas represente apenas mais um fenômeno de homoplasia, como já assinalado para outros elementos florísticos similares encontrados em distintos reinos fitogeográficos paleozoicos.
\end{abstract}

Palavras-chave: Sphenophyta, afloramento Morro do Papaléo, Rio Grande do Sul, Grupo Itararé, Eopermiano.

\section{INTRODUÇÃO}

Diversos trabalhos tratam sobre as ocorrências das Sphenophyta em estratos do Permiano Inferior da bacia do Paraná, uma vez que eles se constituem em um dos grupos vegetais mais comuns e abundantes nesse intervalo estratigráfico da bacia (White, 1908; Lundqvist, 1919; Read, 1941; Rösler, 1974; Millan \& Dolianiti, 1977, 1979, 1980; Andreis et al., 1980; Guerra-Sommer \& Cazzulo-Klepzig, 1981; Cazzulo-Klepzig \& Guerra-Sommer, 1983; GuerraSommer et al., 1985; Oliveira-Babinski, 1988; Iannuzzi, 2000, Rohn \& Rösler, 1987, 2000; Rohn \& Lages, 2000; Zampirolli et al., 2000; Boardman, 2006; Boardman et al., 2007; Roesler et al., 2008; Boardman \& Iannuzzi, 2010).
Em termos de registro fossilífero do Rio Grande do Sul, o afloramento Morro do Papaléo possui uma riqueza ímpar de restos e vestígios de plantas fósseis, constituindo-se em um dos principais afloramentos do estado (síntese em Iannuzzi et al., 2003a,b, 2006, 2007). O grupo das Sphenophyta é um dos mais bem representados nesta localidade, com uma diversidade aparentemente incomum de formas, além da preservação in situ (em posição de vida) de diversos espécimes em um raro registro de associação do tipo auto-parautóctone de membros do grupo (Iannuzzi et al., 2006, 2007). Portanto, um estudo dedicado à classificação taxonômica das Sphenophyta desta localidade vem sendo desenvolvido, a fim de possibilitar a realização de trabalhos futuros com um enfoque mais paleoecológico, evolutivo e 
bioestratigráfico. Deve-se destacar que os táxons referentes às Sphenophyta: Phyllotheca australis Brongniart, 1828 (= P. indica Bunbury, 1879), Stephanophyllites Millan \& Dolianiti, 1980 cf. S. sanpaulensis Millan \& Dolianiti, 1980 e Phyllotheca brevifolia Roesler, Iannuzzi, Boardman \& Baroni, 2008, já foram assinalados para o afloramento Morro do Papaléo (Cazzulo-Klepzig \& Guerra-Sommer, 1983; Iannuzzi, 2000, Iannuzzi et al., 2007; Roesler et al., 2008). Este trabalho dá continuidade ao estudo das formas de Sphenophyta presentes na referida localidade, acrescentando mais um táxon a estas associações únicas na bacia do Paraná.

\section{MATERIAL E MÉTODOS}

Durante o estudo, foram analisados cerca de 40 espécimes, preservados na forma de impressões e contramoldes achatados. Essa última forma de preservação é muito similar às impressões, diferenciando-se, porém, pelo fato de manter parte da tridimensionalidade dos restos, o que permitiu observar de forma mais adequada alguns detalhes dos órgãos vegetais em relação a sua disposição. Os contramoldes encontram-se, por vezes, impregnados de óxidos, enquanto que as impressões apresentam-se com contornos esbranquiçados, bastante contrastantes com a matriz síltico-argilosa de cor avermelhada, o que garante um bom nível de preservação dos detalhes dos espécimes. O material estudado está depositado na "Coleção de Paleobotânica" do Museu de Paleontologia (MP) do Departamento de Paleontologia e Estratigrafia do Instituto de Geociências da Universidade Federal do Rio Grande do Sul (DPE-IG-UFRGS), sob prefixo MP-Pb. Todos os espécimes estudados correspondem a material inédito, com exceção de quatro amostras figuradas como ramos vegetativos de Phyllotheca indica em Cazzulo-Klepzig \& Guerra-Sommer (1983). Cabe ressaltar, que os números de registro das amostras não se encontram mencionados na relação apresentada por Cazzulo-Klepzig \& GuerraSommer (1983, p. 161), tampouco nas legendas das estampas (Cazzulo-Klepzig \& Guerra-Sommer, 1983, p. 167-169), não sendo possível assim saber qual a numeração correspondente a estes espécimes. Deste modo, faz-se necessário aqui a confirmação dos números dos quatro espécimes mencionados: MP-Pb 3644 (Cazzulo-Klepzig \& Guerra-Sommer, 1983, p. 167, est. I, fig. 3), MP-Pb 2544a (Cazzulo-Klepzig \& Guerra-Sommer, 1983, p. 167, est. I, fig. 4), MP-Pb 2525 (Cazzulo-Klepzig \& Guerra-Sommer, 1983, p. 168, est. II, fig. 1) e MP-Pb 3645 (Cazzulo-Klepzig \& Guerra-Sommer, 1983, p. 169, est. III, fig. 5).

As amostras foram preparadas através de procedimentos usuais da preparação paleobotânica, ou seja, desbastadas e limpas com o auxílio de espátulas, estiletes, martelos e talhadeiras de diversos tamanhos, sendo posteriormente analisadas com o auxílio de estereomicroscópio marca Wild. As principais amostras foram registradas através de fotografias digitais, a partir das quais foram elaborados os desenhos.

\section{ÁREA DE ESTUDO}

O afloramento Morro do Papaléo situa-se, aproximadamente, a $100 \mathrm{~km}$ a sudoeste de Porto Alegre, na área de uma antiga mina de caulim (Figura 1A). A sucessão florística encontrada nessa localidade constitui um registro ímpar dentro da bacia do Paraná, uma vez que são observadas três fitozonas distintas distribuídas tridimensionalmente ao longo de uma única seção estratigráfica, além de apresentar um fácil acesso e uma grande riqueza de macrofósseis vegetais (Iannuzzi et al., 2003a,b, 2006). Nesse contexto, podem ser observados dois intervalos fitofossilíferos, um correspondente ao limite superior do Grupo Itararé, e outro, localizado na parte superior do perfil colunar, após uma significativa discordância, onde se observam depósitos da Formação Rio Bonito (Figura 1B).

Os restos fósseis de Sphenophyta encontram-se preservados em distintos níveis (N2 e N4) do Grupo Itararé, onde formam associações autóctones a parautóctones (Figura 1B). A parte superior do afloramento, correspondente à Formação Rio Bonito, diferentemente do usual, não contém restos relativos ao grupo das Sphenophyta (Iannuzzi et al., 2003a,b, 2006).

O perfil colunar da seção aflorante do Morro do Papaléo inicia-se pelos níveis basais N1 e N2 (Figura 1B), representados por ritmitos síltico-argilosos intercalados por níveis de pelitos carbonosos, com estratificação cruzada cavalgante e feições de fluidização associadas (Iannuzzi et al., 2003a,b, 2006). O nível N2 apresenta um conteúdo megaflorístico representado por impressões de frondes de Botrychiopsis Kurtz, 1895, de folhas de Glossopteris Brongniart, 1828, Gangamopteris McCoy, 1847 e do tipo Cordaites Unger, 1850, de sementes do tipo Samaropsis Goeppert, 1864 e Cordaicarpus Geinitz, 1862, além de restos de Sphenophyta atribuídos aos morfogêneros Phyllotheca (Brongniart) Townrow, 1955 e Stephanophyllites.

O nível N4, correspondente ao topo do Grupo Itararé na seção (Figura 1B), é caracterizado por uma sucessão de arenitos finos a muito finos, lenticulares e com laminação ondulada truncante, e siltitos finamente laminados, que apresentam abundantes restos de vegetais e níveis de paleosolos (Iannuzzi et al., 2006). Neste nível está o mais abundante registro das Sphenophyta, bem como impressões foliares relativas aos gêneros Gangamopteris, Glossopteris, Cordaites, Cheirophyllum, Kawizophyllum, e vestígios de sementes dos gêneros Cordaicarpus e Samaropsis. Em relação às Sphenophyta, são encontrados, juntamente com rizomas (tipo Pinularia) e caules do tipo Paracalamites Zalessky, 1927, ramos foliares de diversos tipos que foram referidos às morfoespécies Phyllotheca australis (=P. indica) conforme Cazzulo-Klepzig \& Guerra-Sommer (1983) e $P$. brevifolia, sendo esta uma espécie exclusiva do afloramento, e ao morfogênero Stephanophyllites cf. S. sanpaulensis, todos preservados na forma de impressões ou moldes.

Segundo Iannuzzi et al. (2003a,b, 2006, 2007), os depósitos correspondentes aos níveis N2 e N4 são resultado de sedimentação ocorrida na margem de corpos d'água lacustres ou lagunares, na interface com o ambiente subaéreo, presentes na região durante o Eopermiano (aproximadamente, Neossakmariano), conforme Iannuzzi et al. (2010) e Iannuzzi (2010). 


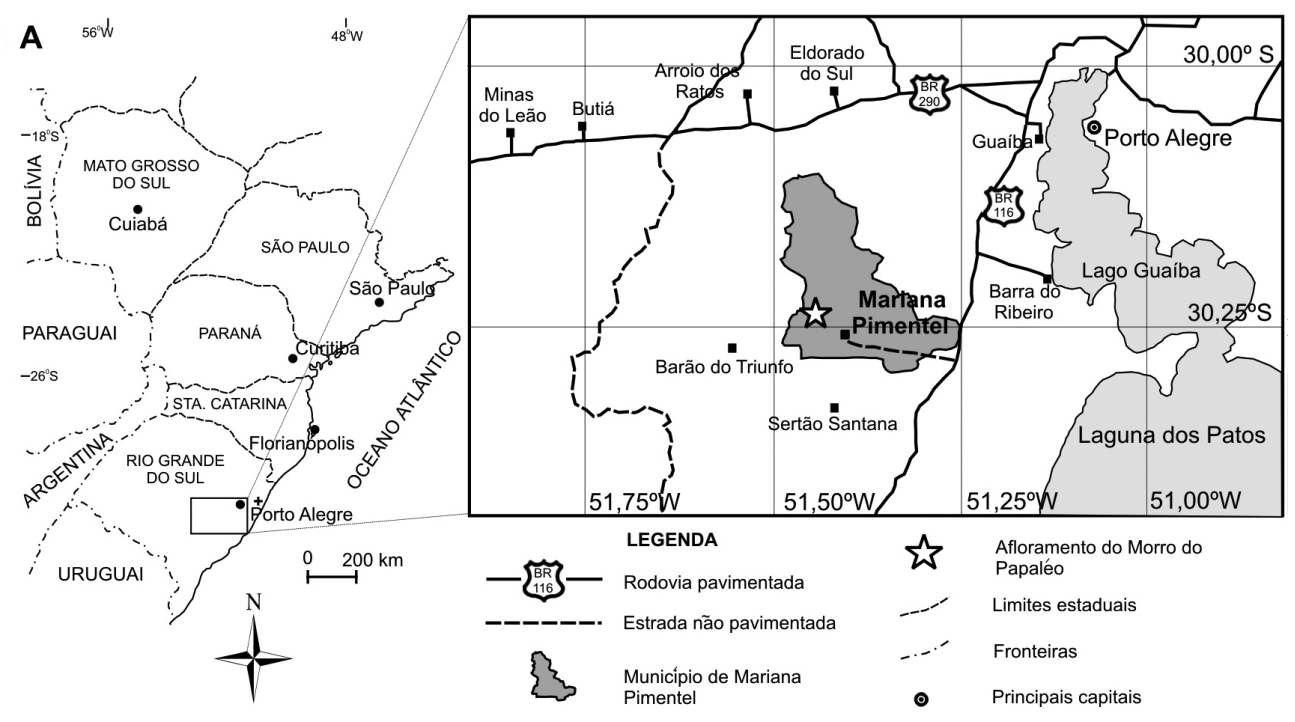

B

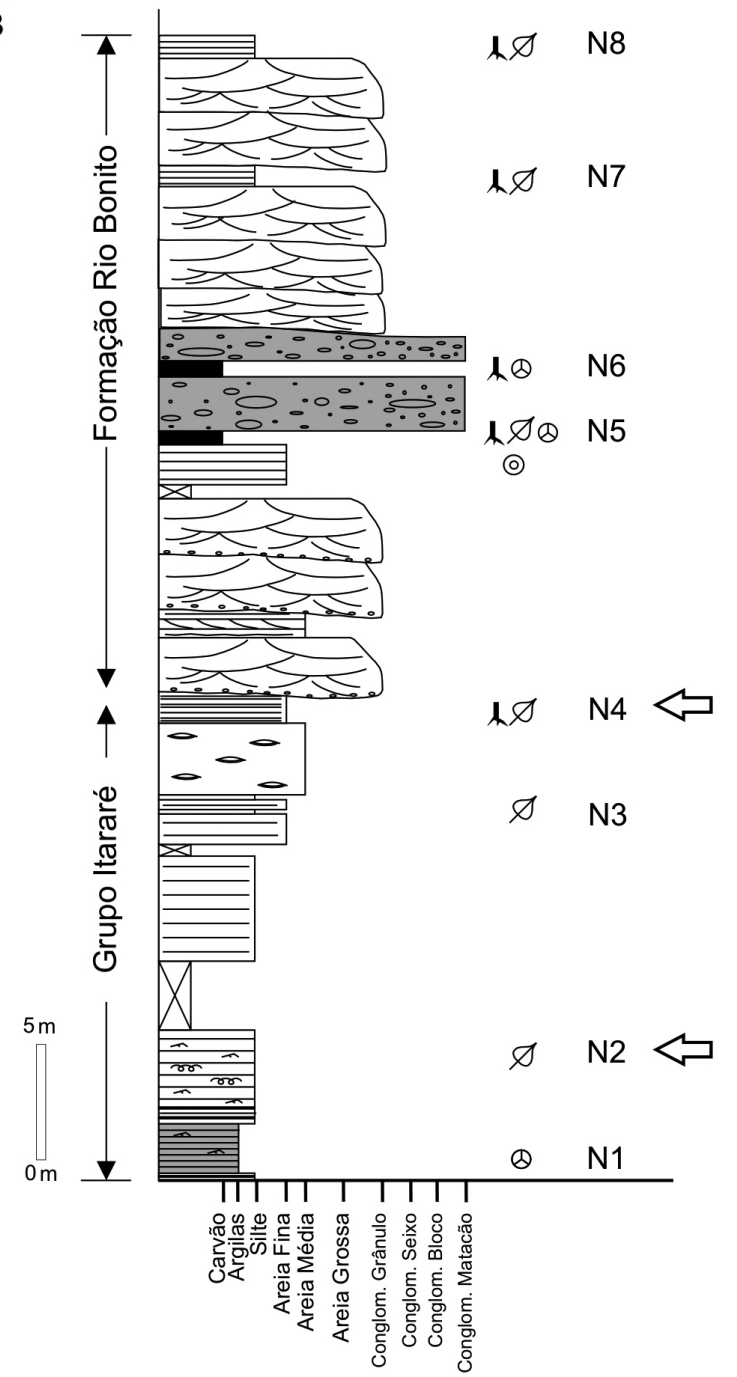

Legenda

Estratificação cruzada acanalada

Estratificação cruzada planar

Estratificação plano paralela

Laminação ondulada truncante Estratificação cruzada cavalgante

Fluidização

Pelitos carbonosos

Matriz carbonosa

Paraconglomerados

N1, N2 Niveis
fossiliferos

$\checkmark \begin{aligned} & \text { Níveis contendo o } \\ & \text { material estudado }\end{aligned}$

Fósseis

$\varnothing \quad$ Plantas fósseis

() Icnofósseis

(2) Palinomorfos

l Paleossolos

Figura 1. A, mapa de localização do Afloramento Morro do Papaléo, município de Mariana Pimentel, RS; B, perfil colunar do Afloramento Morro do Papaléo, mostrando os limites entre o Grupo Itararé e a Formação Rio Bonito, o conteúdo fossilífero e os níveis (setas) dos quais provêm o material de Sphenophyta estudado (modificado de lannuzzi et al., 2003a,b, 2006, 2010; lannuzzi, 2010).

Figure 1. A, location map of the Morro do Papaléo Outcrop, municipality of Mariana Pimentel, Rio Grande do Sul State; B, column of the Morro do Papaléo Outcrop, showing the boundaries between the Itararé Group and Rio Bonito Formation, the fossil content and the levels (arrows) containing the study material of Sphenophyte (modified from lannuzzi et al., 2003a,b, 2006, 2010; lannuzzi, 2010). 


\section{SISTEMÁTICA PALEONTOLÓGICA}

\author{
Divisão SPHENOPHYTA \\ Ordem EQUISETALES \\ Família PHYLLOTHECACEAE Boureau, 1964 \\ Phyllotheca (Brongniart) Townrow, 1955
}

Espécie-tipo. Phyllotheca australis Brongniart, 1828 emend. Townrow, 1955.

Phyllotheca longifolia sp. nov. (Figuras 2-5, Tabela 1)

1983 Phyllotheca indica (auct. non (Bunbury) Pant \& Kidwai, 1968). Cazzulo-Klepzig \& Guerra-Sommer, p. 167, est. I, figs. 3-4 ; p. 168, est. II, fig. 1; p. 169, est. III, fig. 5.

Holótipo. MP-Pb 4400Aa/b.

Parátipos. MP-Pb 2544a/b, 2525, 2591a/b, 2600a/b, 3145, 3644, 3645, 4034, 4117A, 4335, 4339, 4367, 4691Ba/b, 4979, 4980a/b.

Material adicional. MP-Pb 2606, 2755, 2924, 3048, 3054, 3113, 3145, 3404, 3412, 3417, 3646, 3649, 4118, 4347-4348, 4351, 4362, 4367, 4370, 4379, 4381, 4383, 4388, 4652a/b, 4686-4689.

Localidade-tipo e horizonte-tipo. Afloramento Morro do Papaléo, município de Mariana Pimentel, RS; níveis N2 e N4 do topo do Grupo Itararé (Iannuzzi et al., 2003a,b, 2006, 2007). Idade. Eopermiano (Sakmariano tardio).

Etimologia. Referente ao longo comprimento dos folíolos nas suas porções livres, característica diagnóstica desta espécie. Diagnose. Planta herbácea, com caules articulados estriados do tipo Paracalamites; caule principal robusto, com estrias longitudinais, apresentando verticilos foliares com folíolos fusionados na base, formando bainhas sempre mais curtas do que as partes livres dos folíolos. Ramos secundários finos, com estrias longitudinais, portando verticilos foliares compostos por folíolos fusionados na base, formando bainhas que recobrem toda a extensão dos entrenós, cujas partes terminais livres apresentam forma de copo e um comprimento sempre muito inferior às partes livres dos folíolos. Há cerca de $10 \mathrm{a}$ 14 folíolos por verticilo. Folíolos uninervados, muito longos e relativamente largos; porções livres relativamente rígidas, oblongas e com ápices arredondados, por vezes, encurvadas distalmente em direção ao ápice da planta.

Diagnosis. Herbaceous plant, with articulate ribbed axes of type Paracalamites; robust main stem with longitudinal ribs, showing foliar whorls with leaves fused at base, forming sheaths always short than the free portions of leaves. Secondary stems thin, with longitudinal ribs, bearing foliar whorls with fused leaves at base, forming sheaths covering entire internode, with terminal portion frees showing a cuplike shape, always very short in comparison with the free portions of leaves. Each whorl has between 10-14 leaves. Leaves univeined, very long and relatively large, and showing free portions relatively rigid, oblong with rounded apices, sometimes curving upwards in their distal parts.
Descrição. Os espécimes estudados constituem fragmentos das porções média e apical de ramos foliares, bem como de um caule principal, todos articulados, formando nós e entrenós, que se encontram preservados na forma de impressões e contramoldes achatados. A amostra $\mathrm{MP}-\mathrm{Pb}$ $4691 \mathrm{Ba} / \mathrm{b}$ apresenta um fragmento da porção mediana de um caule primário ou principal (Figuras 2B,C), com largura máxima de $15,2 \mathrm{~mm}$ e mais de $200 \mathrm{~mm}$ de comprimento, sendo que os seus entrenós podem alcançar até 20,6 mm de comprimento (Tabela 1). Este caule principal apresenta verticilos foliares, onde os folíolos são fusionados na base, formando bainhas que sempre recobrem os entrenós e se tornam livres próximo ao nível do verticilo subsequente; suas partes livres apresentam entre 8,8 e 9,0 mm de comprimento. O número de folíolos por verticilo é maior do que nove, podendo ser estimado em cerca de 14, uma vez que todos os verticilos encontram-se parcialmente encobertos devido à sua preservação em vista lateral apenas (Figuras 2B,C). Os folíolos em suas partes livres são largos, medindo 2,3 a 3,5 mm de largura, e longos, apresentando de 22,8 até 27,1 mm de comprimento; uninervados, aparentemente oblongos e de lâminas encurvadas basiscopicamente, terminadas em ápices arredondados. Os fragmentos de ramos secundários dos espécimes preservados na forma de impressões e contramoldes achatados, encontradas nos níveis N2 e N4 (Figuras 2A; 3AC; 4A,C,D), são finos, com no máximo 8,2 mm de largura (Tabela 1), e longos, apresentando comprimento maior do que 126,5 mm (Figura 3C). Os ramos possuem estrias e/ou sulcos longitudinais e linhas nodais, normalmente, bem distintas que delimitam entrenós relativamente longos, com comprimentos variando entre 7,9 e 25,4 mm (Tabela 1), os quais diminuem em direção ao ápice. Os verticilos foliares sustentam folíolos fusionados na base que formam bainhas. Estas bainhas são adpressas ao ramo por toda a extensão do entrenó e se tornam livres ao atingirem o nó seguinte, o que lhes confere a aparência de copos em suas porções mais distais (Figuras 2A; 3A,B; 4A,D); estes copos apresentam comprimentos que variam entre 5,3 e 10,9 mm (Tabela 1). Por vezes, podem ser observadas linhas de comissura resultantes da fusão basal dos folíolos nas bainhas (Figuras 2A,B; 3A; 5A,B). O número de folíolos varia entre 13 e 14 por verticilo, levando-se em consideração apenas os espécimes onde havia verticilos totalmente visíveis. Na sua porção livre, os folíolos possuem lâminas oblongas e uninervadas, sendo relativamente largos, apresentando de 1,3 a 3,6 mm em largura, e bastante longos, com comprimentos que variam de 11,5 a 46,6 mm (Tabela 1), finalizando em ápices arredondados. As lâminas apresentam ainda finas enrugações transversais dispostas ao longo da veia média e, ao partirem da bainha, encurvam-se abruptamente, seguindo de modo curvilíneo quase que perpendicularmente ao eixo do ramo, formando assim um suave arco em direção ao ápice da planta (Figuras 2A; 3B,C; 4A). Em espécimes preservados como contramoldes, restritos ao nível N2, a maioria dos ramos, cujas linhas nodais não se mostram tão evidentes, apresenta bainhas que dão uma aparência alada aos caules, em decorrência do tipo de preservação (Figura 4D). Ainda nestes ramos, há algumas bainhas que parecem terminar em apenas dois folíolos 

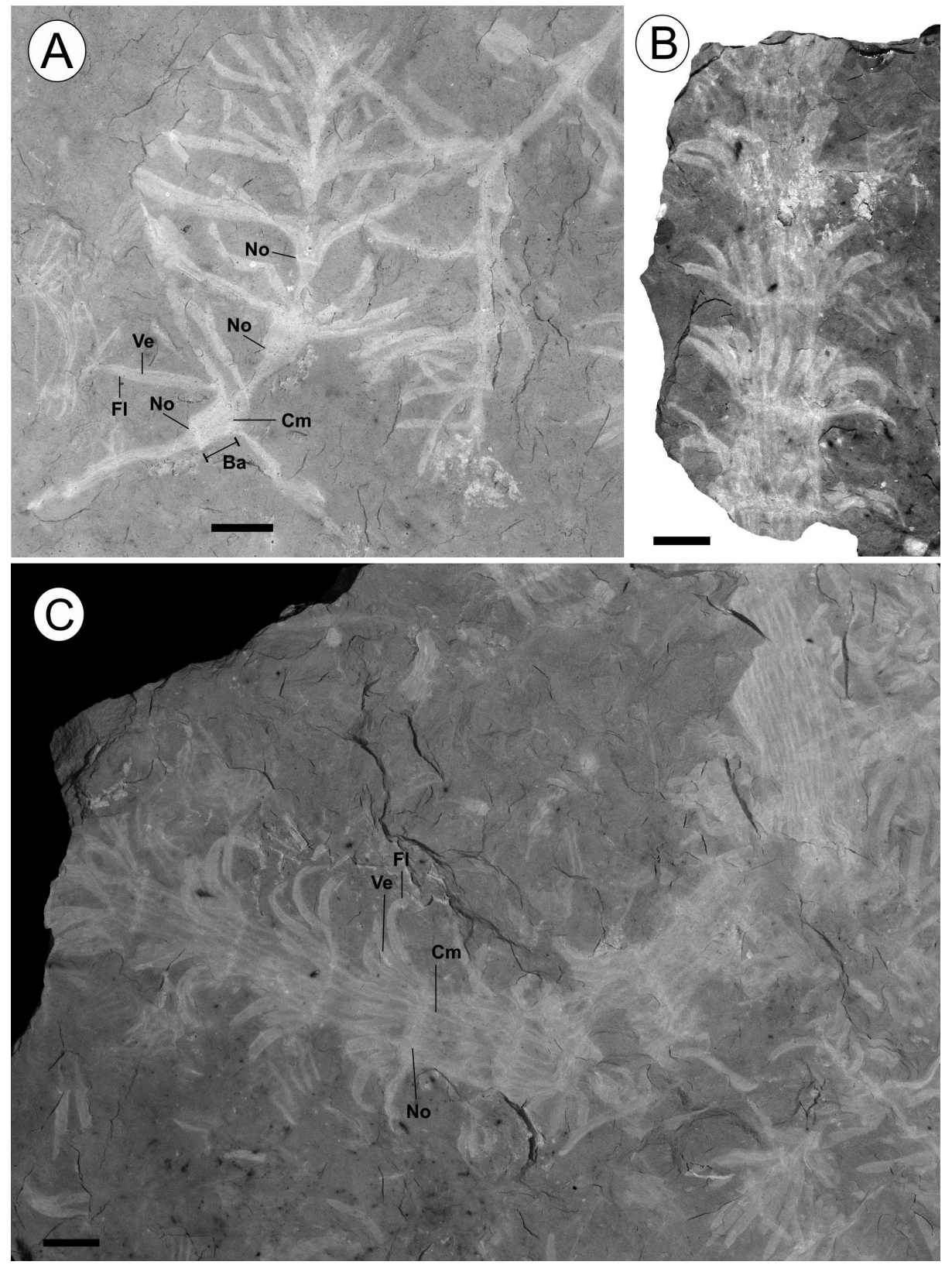

Figura 2. Phyllotheca longifolia sp. nov. A, MP-Pb 4400a, holótipo, vista geral de um ramo vegetativo, mostrando os nós e entre-nós cobertos por bainhas, a distribuição dos longos folíolos organizados em verticilos, e o formato em copo das porções distais das bainhas (Ba), todos caracteres diagnósticos da espécie; B, MP-Pb 4691b, parátipo, detalhe do caule principal, onde se observam cinco nós providos de verticilos foliares, o formato das bainhas e dos folíolos; C, MP-Pb 4691a, parátipo, caule principal, com oito nós e cinco verticilos foliares, evidenciando a robustez do caule e comissuras nas bainhas que representam os limites das partes basais das lâminas foliares fusionadas. Abreviaturas: Ba, porção distal da bainha; $\mathbf{C m}$, linha de comissura; FI, folíolo; $\mathbf{N o}$, nó; Ve, veia média. Escalas = $10 \mathrm{~mm}$.

Figure 2. Phyllotheca longifolia sp. nov. A, MP-Pb 4400a, holotype, general view of vegetative shoot, showing nodes and internodes covered by sheaths, the distribution of very long leaves organized in whorls, and the distal parts of foliar sheaths with "cup-shape" (Ba), all diagnostic features of this species; B, MP-Pb 4691b, paratype, detail of main stem, where five nodes with foliar whorls can be observed beyond the shape of foliar sheaths and leaves; C, MP-Pb 4691a, paratype, main stem with eight nodes and five whorls preserved, showing the robust stem and commissural lines on the sheaths that represents the boundaries of basal part of foliar laminas fused. Abbreviations: Ba, distal portion of sheath; $\mathbf{C m}$, commissural line; FI, leave; No, node; Ve, mid vein. Scale bars $=10 \mathrm{~mm}$.

diametralmente opostos, sugerindo um falso arranjo em pares dos mesmos (ver os dois nós mais basais de MP-Pb 2600, Figura 4D). No entanto, ao longo dos ramos destes mesmos espécimes, outros verticilos sustentam mais de dois folíolos, tendo sido constatados entre cinco e nove nestes casos (ver os dois nós mais apicais de MP-Pb 2600, Figura 4D). Situação similar pode ser observada em uns poucos espécimes coletados no nível N4, como por exemplo, em MP-Pb 3645 (Figura 4A, compare o verticilo inferior com o superior). Deste modo, conclui-se que a disposição em pares dos folíolos, vista em alguns espécimes, corresponde, na realidade, a um artefato tafonômico criado pela visão lateral que se tem dos ramos e verticilos, conforme o tipo de preservação do espécime (tridimensional) e o modo de partição da amostra quando da sua coleta. 
Tabela 1. Phyllotheca longifolia sp. nov. Medidas $(\mathrm{mm})$ das principais partes vegetativas do holótipo (*) e parátipos da espécie. Níveis estratigráficos conforme lannuzzi et al. (2003a,b, 2006, 2010) e lannuzzi (2010).

Table 1. Phyllotheca longifolia sp. nov. Measurements $(\mathrm{mm})$ of main vegetative parts of holotype $\left(^{*}\right)$ and paratypes of this species. Stratigraphic levels according to lannuzzi et al. (2003a,b, 2006, 2010) e lannuzzi (2010).

\begin{tabular}{|c|c|c|c|c|c|c|c|c|c|}
\hline $\begin{array}{l}\text { Espécime } \\
\text { MP-Pb }\end{array}$ & $\begin{array}{l}\mathrm{N}^{\circ} \text { entre-nós } \\
\text { completos }\end{array}$ & $\begin{array}{l}\text { Largura dos } \\
\text { entre-nós }\end{array}$ & $\begin{array}{l}\text { Comprimento } \\
\text { dos entre-nós }\end{array}$ & $\begin{array}{l}\text { Comprimento } \\
\text { do copo da } \\
\text { bainha }\end{array}$ & $\begin{array}{c}\mathrm{N}^{\circ} \text { folíolos } \\
\text { por } \\
\text { verticilo }\end{array}$ & $\begin{array}{l}\mathrm{N}^{\circ} \text { folíolos } \\
\text { completos }\end{array}$ & $\begin{array}{l}\text { Largura } \\
\text { folíolos }\end{array}$ & $\begin{array}{l}\text { Comprimento } \\
\text { folíolos }\end{array}$ & $\begin{array}{c}\text { Nível } \\
\text { Estratigráfico }\end{array}$ \\
\hline \multicolumn{10}{|c|}{$\begin{array}{c}\text { Caule } \\
\text { Principal }\end{array}$} \\
\hline $4691 \mathrm{Ba} / \mathrm{b}$ & 4 & $13,1-15,2$ & $19,7-20,6$ & $8,8-9,0$ & $>9$ & 5 & $2,3-3,5$ & $22,8-27,1$ & $\mathrm{~N} 4$ \\
\hline \multicolumn{10}{|c|}{$\begin{array}{c}\text { Ramos } \\
\text { Secundários }\end{array}$} \\
\hline 2525 & 1 & $2,4-2,7$ & - & - & $>12$ & 4 & $1,3-2,6$ & $16,7-23,4$ & $\mathrm{~N} 4$ \\
\hline 2544 & - & - & - & - & 13 & 5 & $2,9-3,6$ & $38,0-46,6$ & $\mathrm{~N} 4$ \\
\hline 2591 & - & $2,1-2,5$ & - & - & $>4$ & 2 & $2,6-2,8$ & $14,8-19,4$ & $\mathrm{~N} 2$ \\
\hline 2600 & 3 & $4,1-8,2$ & $9,8-14,7$ & - & $>6$ & 3 & $1,8-2,9$ & $18,0-31,7$ & $\mathrm{~N} 2$ \\
\hline 3145 & - & - & - & - & 14 & 8 & $2,8-3,5$ & $36,2-46,3$ & $\mathrm{~N} 4$ \\
\hline 3644 & - & 4,3 & - & 9 & $>10$ & 2 & 2,4 & $26,3-37,3$ & N4 \\
\hline 3645 & 2 & $5,0-5,6$ & 25,4 & $7,4-7,5$ & $>7$ & - & - & - & $\mathrm{N} 4$ \\
\hline 4034 & - & - & - & - & $>5$ & 1 & $2,4-2,9$ & 28,2 & $\mathrm{~N} 4$ \\
\hline $4117 \mathrm{~A}$ & 3 & $3,9-4,5$ & - & - & $>4$ & 2 & $2,0-2,3$ & $11,5-18,4$ & $\mathrm{~N} 4$ \\
\hline 4335 & 4 & $3,4-3,8$ & $8,4-13,6$ & - & $>5$ & 7 & $2,0-2,7$ & $15,5-28,7$ & $\mathrm{~N} 4$ \\
\hline 4339 & 3 & $3,7-5,2$ & $17,5-25,1$ & $6,2-6,3$ & $>9$ & - & $1,7-2,8$ & - & $\mathrm{N} 4$ \\
\hline 4367 & 2 & $2,9-4,6$ & $12,4-17,7$ & - & $>8$ & 6 & $1,6-2,2$ & $20,6-29,0$ & $\mathrm{~N} 4$ \\
\hline $4400 \mathrm{Aa}^{*}$ & 5 & $4,6-7,0$ & $7,9-22,0$ & $5,8-8,0$ & $>9$ & 5 & $2,3-2,7$ & $21,7-30,1$ & $\mathrm{~N} 4$ \\
\hline 4979 & 3 & $4,3-5,1$ & $20,1-25,4$ & $9,7-10,9$ & $>4$ & - & - & - & N4 \\
\hline $4980 \mathrm{a}$ & 6 & $3,6-4,8$ & $11,6-17,5$ & $5,3-7,6$ & $>7$ & 7 & $2,3-2,9$ & $22,7-33,4$ & N4 \\
\hline
\end{tabular}

\section{DISCUSSÃO}

A forma descrita aqui se assemelha muito à do morfogênero angárico Phyllopitys Zalessky, 1918 (in Neuburg, 1948), assinalado originalmente para o Eopermiano da Rússia, nas bacias de Kuznetz e Tunguska (Meyen, 1971). Esta semelhança verifica-se por apresentar folíolos largos, compridos, de distribuição espacial similar, especialmente, nos contramoldes restritos ao nível N2, que apresentam características semelhantes às das amostras russas na porção apical dos ramos, onde os folíolos dispõem-se aos pares (ver MP-Pb 2600; Figura 4D), como aquela citada na diagnose de Phyllopitys reproduzida por Neuburg (1948, p. 254-255) e no espécimes bem ilustrados, posteriormente, por Meyen (1971, pl. 11, figs. 79-80, pl. 12, figs. 81-86).

Schmalhausen (1879) classificou alguns espécimes sob o nome de Cyclopitys, um morfogênero associado ao grupo das Taxodiaceae (atualmente, em Cupressaceae). O gênero foi revisto por Zalessky (1918), que separou essa forma em um novo morfogênero, Phyllopitys, incluído no grupo das coníferas. O grupo foi reavaliado por Neuburg (1948) que considerou as amostras desse morfogênero de afinidade incerta, mas comentou que alguns espécimes guardavam semelhança com o grupo das Sphenophyta. Posteriormente, Rasskazova (1961) associou os espécimes de Phyllopitys a ramos jovens de Annulina neuburgiana Radczenko, 1934. Chachlov (1964), com base em frutificações, associou o morfogênero ao grupo das esfenófitas e excluiu alguns exemplares do grupo. Meyen (1971) apresentou novas evidências que corroboravam a vinculação desta forma às esfenófitas, com base em amostras encontradas pelo próprio autor em sedimentos do Eopermiano da bacia de Tunguska River. Então, Meyen (1971) concluiu que Phyllopitys não apresentava afinidade com Annulina ou com o grupo das coníferas, validando-o como um morfogênero ligado ao grupo das Sphenophyta e, provavelmente, associado à Família Tschernoviaceae.

Meyen (1971) também citou as características e os principais problemas que precisavam ser solucionados na descrição do gênero Phyllopitys: (i) a ausência de uma marcação nítida da linha nodal, apesar da existência de indícios da sua presença; (ii) os espécimes demonstravam que os folíolos eram decorrentes até o nó, indicando a presença de bainha, mas o graus de preservação dos mesmos não permitia uma descrição mais apurada das bainhas; (iii) a probabilidade de que as bainhas, a exemplo do que acontece no gênero atual Equisetum, cobrissem todo o entrenó, incluindo o nó subsequente, mas tal característica necessitava de comprovação. Pode-se concluir, então, que a dificuldade na determinação exata de tais características torna a comparação de Phyllopitys praticamente inviável com quaisquer formas mais bem definidas, incluindo a aqui estudada.

Além disso, na diagnose original do material angárico as folhas são definidas como alternas, dispostas em pares. Como mencionado acima, apenas alguns dos ramos foliares dos 
espécimes encontrados no nível N2 são semelhantes aos de Phyllopitys, principalmente, quanto à disposição dos folíolos. Um detalhe interessante é observado em MP-Pb 3645 (Figura 4A), onde no primeiro verticilo observa-se a distribuição em pares descrita originalmente por Zalessky (1918), mas no segundo verticilo, onde se tem uma visão em três dimensões do espécime, ocorrem cerca de sete folíolos visíveis. A partir disto, constata-se nitidamente que a presença de apenas dois folíolos é uma feição tafonômica relacionada ao tipo de visão lateral que se tem dos verticilos de alguns espécimes. Deste modo, conclui-se que a forma aqui descrita não apresenta folíolos inseridos aos pares, mas um número que varia de 2 a 14, dependendo da vista que se tenha dos verticilos, o que impossibilita que os restos encontrados no Morro do Papaléo sejam classificados nesse morfogênero, mesmo com as grandes semelhanças na morfologia dos ramos e dos folíolos.

Por fim, alguns espécimes de Phyllopitys apresentam ramos com porções férteis, que são indistinguíveis de
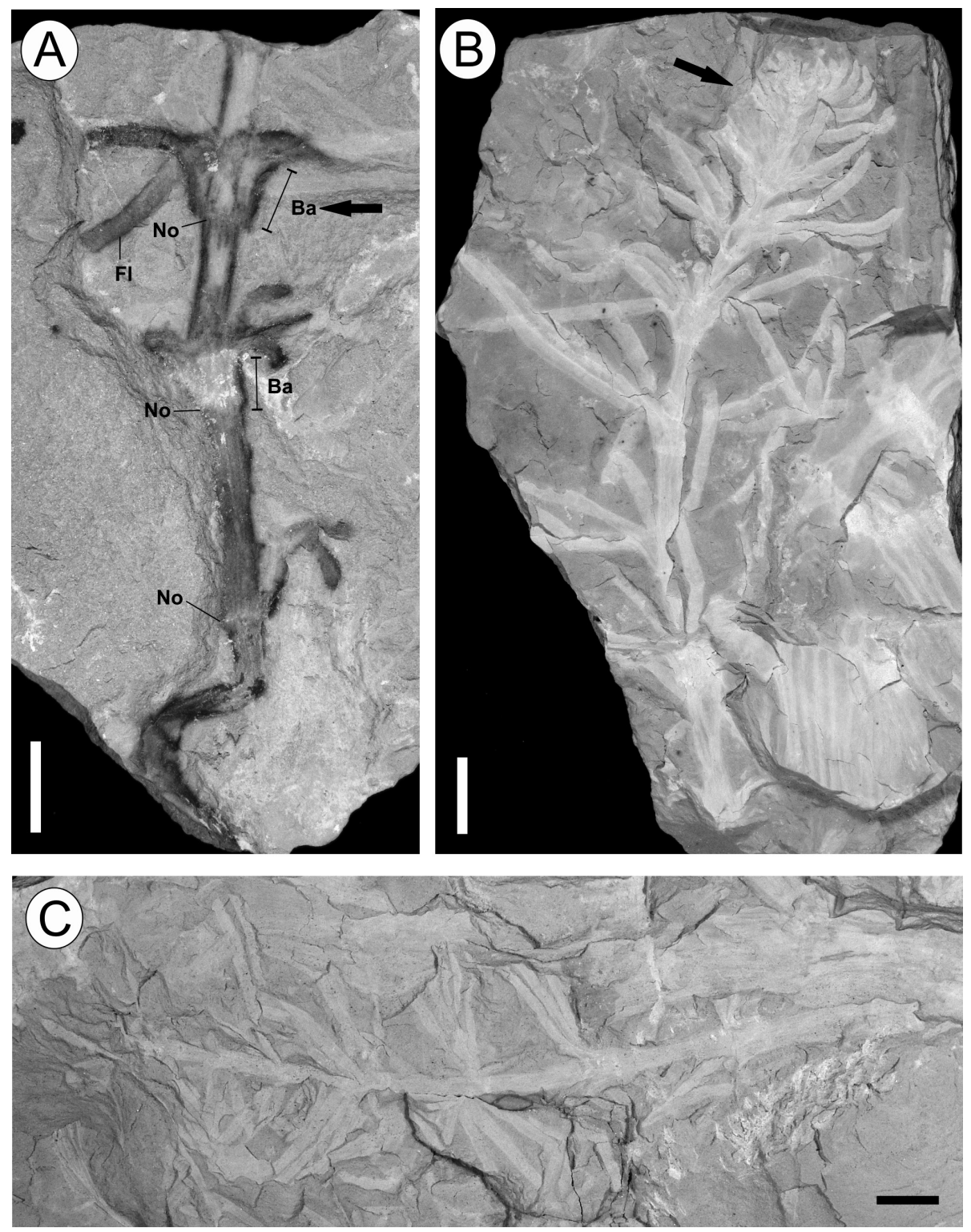

Figura 3. Phyllotheca longifolia sp. nov. A, MP-Pb 4979, detalhe de um ramo secundário com três nós, evidenciando o formato em copo das bainhas, bem como um nó nítido, subjacente ao verticilo foliar mais superior (seta), que mostra a bainha afastando-se do caule somente após ultrapassar o nó seguinte; B, MP-Pb 4980a, ramo secundário mostrando o ápice completamente preservado, de onde parte uma coroa de folíolos distais (seta), morfologicamente semelhantes aos mais proximais e que diferem apenas no seu tamanho reduzido, note também o comprimento longo dos folíolos mais proximais; C, MP-Pb 4339, ramo secundário incompleto com seis nós preservados, evidenciando os longos ramos e folíolos que esta forma pode apresentar. Abreviaturas: Ba, porção distal da bainha; FI, folíolo; No, nó. Escalas = 10 mm.

Figure 3. Phyllotheca longifolia sp. nov. A, MP-Pb 4979, detail of a secondary shoot, with three nodes preserved, showing the cup-shape of sheaths and a well-sharp node, underlying to the uppermost foliar whorl, that shows the sheath moving away from the stem only after it pass through the next node; B, MP-Pb 4980a, secondary shoot showing the entire apex preserved, bearing a crown of distal leaves morphologically similar to the proximal ones except for their drastic reduction in lengths, also note the very long length of proximal leaves; $\mathbf{C}$, MP-Pb 4339 , incomplete secondary shoot with six nodes preserved, showing very long leaves. Abbreviations: Ba, distal portion of sheath; FI, leave; No, node. Scale bars $=10 \mathrm{~mm}$. 
Tschernovia Zalessky, 1918, segundo Meyen (1971). Como a forma aqui estudada apresenta apenas porções vegetativas da planta, uma inclusão em Phyllopitys seria desaconselhável.

O morfogênero Annulina, que foi originalmente registrado para o Eopermiano das bacias de Kuznetzk, Gorlovsk, Petchora e Tunguska (Boureau, 1964), é considerado uma forma próxima a Phyllopitys e, por isso, o material estudado deve ser também comparado a este. Meyen (1971) já havia comentado que existe diferenças entre os morfogêneros
Annulina e Phyllopitys e que, apesar de algumas características em comum, como as bordas foliares paralelas, bainhas muito curtas em relação às partes livres dos folíolos, as formas incluídas em Annulina se diferenciam por ter as partes distais de seus folíolos em curvatura falciforme, e por apresentarem os verticilos inseridos em uma disposição oblíqua em relação ao eixo caulinar. Estas mesmas feições diferenciam Phyllotheca longifolia sp. nov. das formas de Annulina, pois no material brasileiro os folíolos apresentam lâminas mais
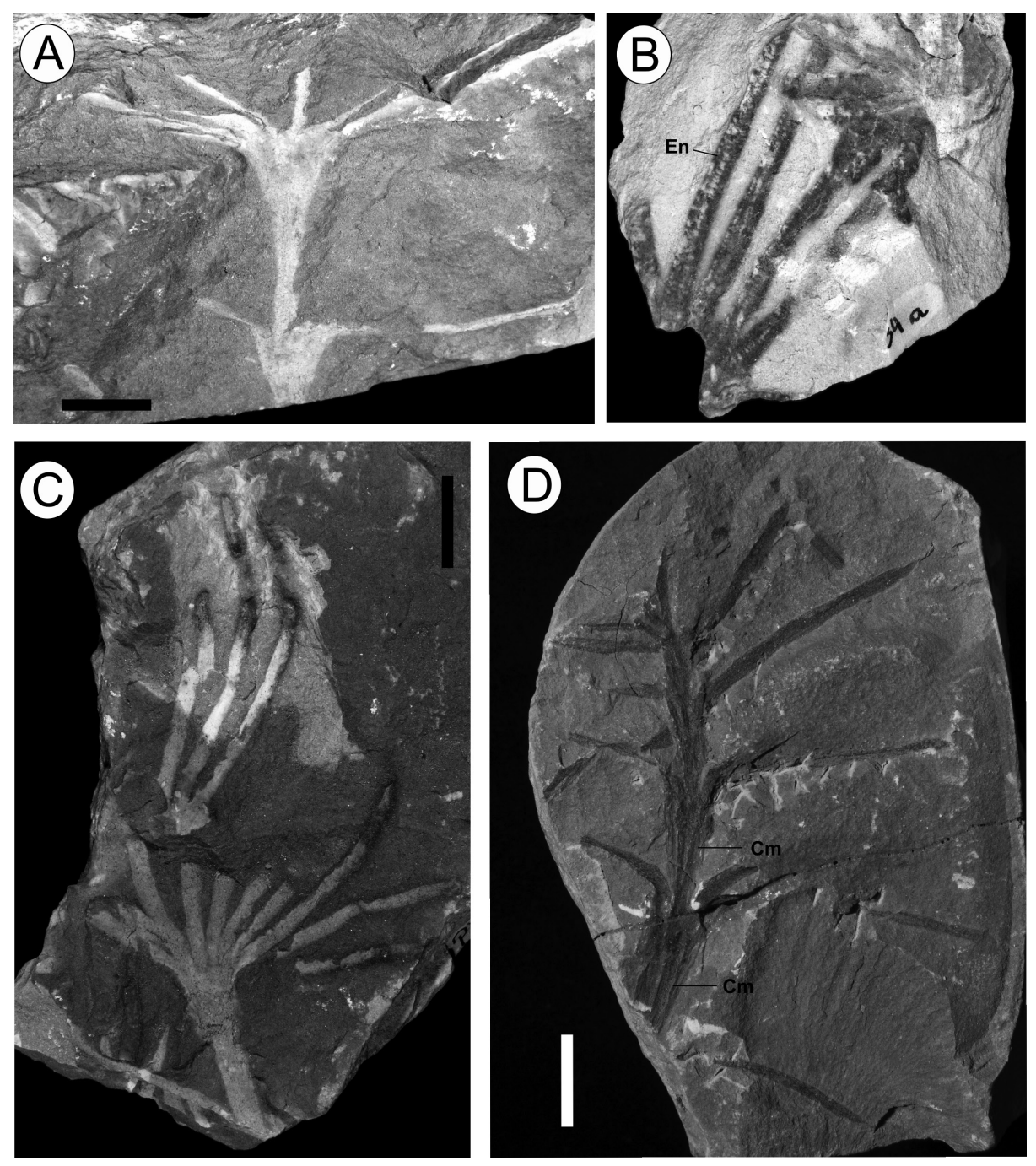

Figura 4. Phyllotheca longifolia sp. nov. A, MP-Pb 3645, detalhe de dois verticilos foliares, onde se pode observar, através da comparação entre o verticilo inferior e superior, que a distribuição aos pares dos folíolos é apenas um artefato tafonômico, note os longos folíolos (espécime ilustrado em Cazzulo-Klepzig \& Guerra-Sommer, 1983, est. III, fig. 5, como P. indica); B, MP-Pb 4034, detalhe dos folíolos, mostrando claramente uma veia mediana e a presença de enrugações transversais ao longo das lâminas foliares; C, MP-Pb 3644, detalhe de dois verticilos foliares, onde se pode observar no inferior o formato em copo da porção distal da bainha e a disposição e longo comprimento dos folíolos (ilustrado em Guerra-Sommer \& Cazzulo-Klepzig, 1983, est. I, fig. 3, como P. indica); D, MP-Pb 2600, detalhe de um ramo secundário de amostra proveniente do nível N2, mostrando uma outra forma de preservação que simula uma distribuição aos pares dos folíolos, apenas um artefato tafonômico, e onde também se pode observar as linhas de comissuras resultantes da fusão basal dos folíolos que formam as bainhas que recobrem inteiramente os entre-nós. Abreviaturas: $\mathbf{C m}$, linha de comissura; En, enrugações transversais. Escalas = $10 \mathrm{~mm}$.

Figure 4. Phyllotheca longifolia sp. nov. A, MP-Pb 3645, detail of two foliar whorls, where one can observe, through comparison between the lower and upper whorls, that the distribution of leaves in pairs its only a taphonomic artifact, note the very long leaves (specimen illustrated in Guerra-Sommer \& Cazzulo-Klepzig, 1983, est. III, fig. 5, as P. indica); B, MP-Pb 4034, detail of leaves, showing clearly a mid vein and transversal shrinks through the foliar laminas; C, MP-Pb 3644, detail of two foliar whorls, the lowest one shows the "cup-shape" of distal part of sheath and the arrangement of the leaves (specimen illustrated in Guerra-Sommer \& Cazzulo-Klepzig, 1983, Est. I, fig. 3, as P. indica); D, MP-Pb 2600, detail of secondary shoot of specimens recovered from level N2, showing a different form of preservation that simulates a distribution in pairs of leaves, only a taphonomic artifact, also note the commissural lines (ribs), resulting from basal fusion of leaves which form the sheaths that overlying the entire internodes. Abbreviations: $\mathbf{C m}$, commissural line; En, transversal shrinks. Scale bars $=10 \mathrm{~mm}$. 

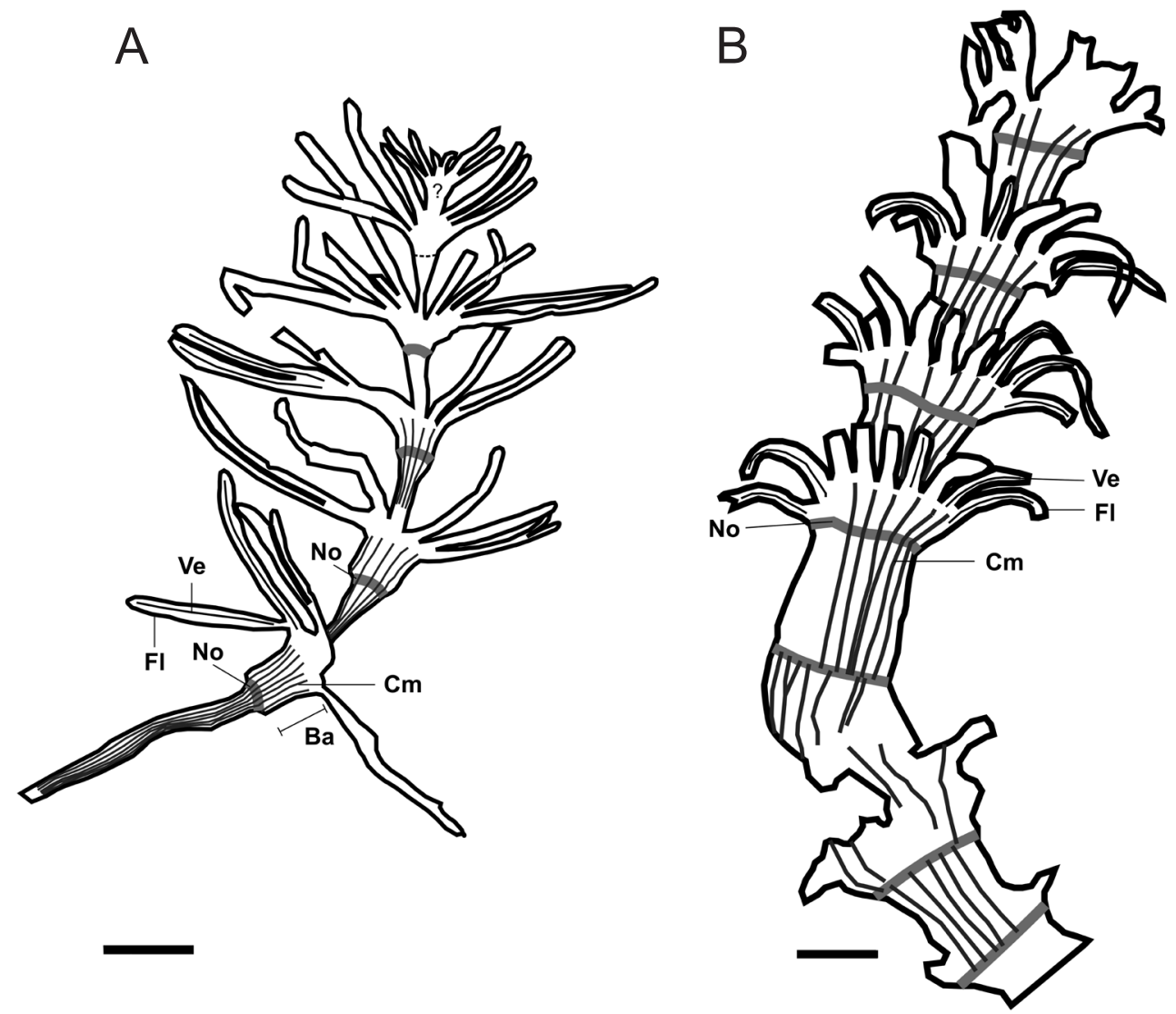

Figura 5. Desenhos esquemáticos do holótipo e do parátipo. A, MP-Pb 4400a, holótipo, ramo evidenciando as características distintivas da espécie, tais como (i) bainhas adpressas recobrindo todo o entre-nó, afastando-se do caule apenas na altura dos nós quando assume uma forma de copo, e (ii) verticilos foliares que apresentam folíolos longos, oblongos, de ápices arredondados e uninervados, (iii) bem como a organização em coroa dos folíolos terminais no ápice do ramo; B, MP-Pb 4691a, parátipo, caule principal evidenciando suas principais características, tais como (i) a presença de linhas de comissura resultante da fusão basal dos folíolos e (ii) o afastamento das bainhas do caule em suas porções distais, apenas na altura dos nós, formando os verticilos foliares. Abreviaturas: Ba, porção distal da bainha; Cm, linha de comissura; FI, folíolo; No, nó; Ve, veia média. Escalas $=10 \mathrm{~mm}$.

Figure 5. Schematic drawings of the holotype and paratype. A, MP-Pb 4400a, holotype, branch showing the distinctive characters of the species, such as (i) adpressed sheaths overlying the entire internode, only moving away from the stem when it reach the nodes acquiring a "cup-like" shape, and (ii) foliar whorls that bear very long and oblongs leaves with rounded apex and univeined lamina, as well (iii) the organization in crown of terminal leaves in the apex of branch; B, MP-Pb 4691a, paratype, main stem showing the essential features, as (i) the presence of commissural lines resulting from the basal fusion of the leaves, and (ii) the sheaths that moves away from the stem in their distal portions, only at the level of nodes, forming foliar whorls. Abbreviations: Ba, distal portion of sheath; Cm, commissural line; FI, leave; No, node; Ve, mid vein. Scale bars $=10 \mathrm{~mm}$.

retas, apenas suavemente encurvadas em direção ao ápice, e suas inserções se dão sempre de modo perpendicular ao eixo caulinar que os sustenta (Figuras 2A,B; 3A,B; 4A,D).

Por fim, tem-se o morfogênero Phyllotheca que também apresenta formas próximas às do material em análise. Este morfogênero foi erigido por Brongniart (1828), referindo-se ao material proveniente de Hawkesbury River, Austrália. Posteriormente, Townrow (1955) propôs uma emenda à diagnose original, considerando outras formas relacionadas ao gênero, e indicou $P$. australis como a espécie tipo.

Phyllotheca se distingue dos demais morfogêneros por possuir folíolos de dimensões homogêneas (não apresentam heterofolia), finos, planos, de margens inteiras, uninervados, com nervura mediana pouco nítida, inseridos perpendicularmente em relação ao eixo do caule ou ramo que os sustentam. Na base, os folíolos formam uma bainha contínua, que raramente ultrapassa mais do que a metade do seu comprimento, bainha que apresenta ranhuras de comissuras que não atingem a porção livre dos folíolos. Uma característica da bainha foliar, que se repete nas diversas formas atribuídas ao gênero, é o formato afunilado de sua porção proximal, bem como sua expansão para além do caule, formando uma lâmina em forma de disco (Boureau, 1964). Normalmente, cada bainha que se origina em um nó, recobre todo o entrenó subsequente de forma adpressa, afastando-se do ramo apenas ao atingir a altura do próximo nó (Boureau, 1964; Meyen, 1971).

Os espécimes estudados conferem com a caracterização feita acima para Phyllotheca, o que justifica sua inclusão neste morfogênero. No entanto, os espécimes em estudo apresentam algumas diferenças em relação à maioria das outras formas já descritas para Phyllotheca, sendo as mais marcantes: a robustez e o longo comprimento dos folíolos e sua forma oblonga, com as bordas das lâminas foliares 
correndo paralelas, além da inserção de folíolos ao longo do caule principal.

De qualquer modo, existe alguma semelhança nos folíolos de Phyllotheca stellifera Schmalhausen, 1879, mas nesta morfoespécie a bainha é adpressa, ou tenuamente afastada do caule, enquanto a forma aqui descrita apresenta bainhas mais desenvolvidas.

Existe também alguma semelhança com Phyllotheca deliquescens (Goeppert) Schmalhausen, 1879, principalmente no formado das bainhas e dos folíolos. Entretanto, essa morfoespécie apresenta partes férteis, e tem como características os folíolos mais largos na base e mais longos que a nervura mediana, ambas feições não observadas nos espécimes estudados.

Outra forma semelhante à estudada é Phyllotheca griesbachii Zeiller, 1892 devido ao fato de possuir supostamente folíolos muito mais longos do que o de outras espécies. Entretanto, esta espécie foi considerada por diversos autores (e.g. Maheshwari,1968; McLoughlin, 1992; Roesler et al., 2008) como uma sinonímia de $P$. australis, da qual a forma estudada difere, principalmente, pela forma dos folíolos. Em $P$. australis, os folíolos são lanceolados e possuem ápices agudos, enquanto que em $P$. longifolia sp. nov. eles são oblongos, com a lâmina foliar larga e ápice arredondado. Além disso, as bainhas foliares também apresentam uma diferença marcante entre as duas formas. As bainhas em P. australis são proporcionalmente longas, em relação às porções livres dos folíolos, e claramente afastadas do caule, apresentando formato de taça ou funil. Em P. longifolia sp. nov. a porção livre das bainhas é relativamente curta e próxima do caule, e em forma de copo.

Assim, o material aqui descrito apresenta-se como uma forma única e distinta de outras apresentadas na literatura. Conclui-se, por conseguinte, que se trata de uma nova espécie de Phyllotheca, morfologicamente semelhante a algumas formas angáricas e denominada aqui como $P$. longifolia sp. nov. Assim sendo, as amostras classificadas como $P$. indica no trabalho de Cazzulo-Klepzig \& Guerra-Sommer (1983) citadas neste trabalho, são consideradas sinonímias de $P$. longifolia sp. nov..

\section{CONSIDERAÇÕES FINAIS}

O presente trabalho trouxe uma nova espécie semelhante morfologicamente às formas angáricas Phyllopitys e Annulina. Entretanto, uma comparação com o morfogênero Phyllotheca, bem como sua localização geográfica nos leva a incluí-la no morfogênero Phyllotheca como P. longifolia sp. nov. A nova forma encontra-se restrita aos depósitos do topo do Grupo Itararé, no Rio Grande do Sul, tendo sido assinalada para, pelo menos, dois níveis estratigráficos distintos (N2 e N4). Dada a sua relativa abundância local e a sua ocorrência em mais de uma camada fossilífera, pode-se dizer que esta nova espécie poderá configurar-se em um novo táxon índex nos zoneamentos fitoestratigráficos já propostos para esta porção da bacia do Paraná, conforme Guerra-Sommer \& Cazzulo-Klepzig (1993) e Iannuzzi et al. (2007). Neste sentido, $P$. longifolia sp. nov. pode ser considerada um táxon típico da Zona de $P$. australis (sensu Iannuzzi et al., 2007), estendendo-se pelas duas subzonas, i.e. Gangamopteris obovata e Botrychiopsis plantiana, conforme a distribuição sugerida por Iannuzzi et al. (2003a,b; 2007, 2010) para essas unidades ao longo do perfil do Morro do Papaléo.

Por fim, a semelhança que Phyllotheca longifolia sp. nov. apresenta com as formas angáricas de Phyllopitys deve ser interpretada como um possível fenômeno de homoplasia, comum às porções vegetativas do grupo das esfenófitas durante o Paleozoico (Meyen, 1967, 1971, 1987). Para o morfogênero Phyllotheca, de ampla distribuição geográfica, há pelo menos duas famílias, baseadas em estruturas reprodutivas que podem ser vinculadas a este morfotipo foliar, a Família Tschenorviaceae, restrita ao Reino Angara, e a Família Gondwanostachyaceae, encontrada no Reino Gondwana (Meyen, 1971, 1987). Outro bem relatado exemplo de homoplasia entre esfenófitas do grupo das esfenofilales referese a presença do morfogênero cosmopolita Sphenophyllum no Permiano da Argentina, onde foi vinculado, a partir da presença de estruturas reprodutivas, a uma família totalmente diferente daquelas assinaladas para outras partes do mundo (Cúneo et al., 1993). Recentemente, tem-se registrado para Índia e Brasil ramos foliares do tipo Phyllotheca em conexão orgânica com, pelo menos, mais dois tipos de frutificações, i.e. Giridia e Notocalamites, mostrando que este mesmo morfotipo foliar pode ser associado a diferentes famílias através do Gondwana (Boardman, 2006; Boardman \& Iannuzzi, 2010).

Segundo Meyen $(1967,1987)$, a homoplasia de partes vegetativas parece ter sido um fenômeno recorrente entre os grupos vegetais que habitaram diferentes reinos florísticos no Neopaleozoico, especialmente, entre aqueles encontrados em áreas sobre regimes climáticos semelhantes, como no caso dos vegetais presentes nos reinos Angara e Gondwana. Neste sentido, as similitudes morfológicas encontradas se explicariam pela evolução convergente de caracteres adaptativos às condições paleoclimáticas semelhantes. Portanto, não seria improvável o registro de formas com porções vegetativas quase idênticas entre Angara e Gondwana, como constatado para a nova espécie aqui descrita. Porém, enquanto as porções férteis relacionadas a Phyllotheca longifolia sp. nov. não forem encontradas, a sua afinidade botânica a nível de família permanece incerta.

Tendo em vista as considerações mencionadas acima, há uma expectativa de que a diversidade incomum de morfoespécies baseadas em caracteres vegetativos de esfenófitas encontrada nos níveis N2 e, principalmente, N4 do afloramento Morro do Papaléo, representada por Stephanophyllites cf. S. sanpaulensis, Phyllotheca australis, $P$. brevifolia e $P$. longifolia sp. nov., possa estar refletindo distintas espécies naturais. Ou seja, espera-se que cada uma das morfoespécies presentes nestes níveis esteja associada a um diferente tipo de estrutura reprodutiva, constituindose assim em uma comunidade ribeirinha com excepcional riqueza de espécies de esfenófitas, onde todas conviveram juntas, em um mesmo "ecoespaço" ou habitat. Este fato é 
bastante incomum entre os representantes herbáceo-arbustivos do grupo das Sphenophyta, no Paleozoico, que normalmente constituíam comunidades monoespecíficas à beira dos corpos d'água (DiMichele \& Hook, 1992).

\section{AGRADECIMENTOS}

Os autores agradecem ao Conselho Nacional de Desenvolvimento Científico e Tecnológico (CNPq), pelo apoio concedido através de bolsas (processos PQ309322/20073, 130053/2005-8 e PQ305687/2010-7) e auxílios (Processo 483463/2007-8), fundamental para a realização deste trabalho; à Fundação de Amparo à Pesquisa do Estado do Rio Grande do Sul (FAPERGS) pelo auxílio concedido (Processo PqG1015846), e a L.F. Lopes, pelas fotos do material estudado.

\section{REFERÊNCIAS}

Andreis, R.R.; Cazzulo-Klepzig, M.; Guerra-Sommer, M. \& Zimermann, L. 1980. Considerações sobre um afloramento fossilífero do Grupo Itararé: Fazenda Goulart, Francisquinha, Município de São Jerônimo, RS. Boletim IG-USP, 11:85-97.

Boardman, D.R. 2006. Tafoflora de Taió, Santa Catarina (Permiano Inferior, Formação Rio Bonito, Bacia do Paraná). Programa de Pós-Graduação em Geociências, Universidade Federal do Rio Grande do Sul, Dissertação de Mestrado, 112 p.

Boardman, D.R. \& Iannuzzi, R. 2010. Presence of the genus Giridia in the Paraná Basin (Lower Permian, Rio Bonito Formation). Revista Brasileira de Paleontologia, 13:5-12. doi: 10.4072/ rbp.2010.1.01

Boardman, D.R.; Iannuzzi, R. \& Dutra, T.L. 2007. Esfenófitas da Formação Rio Bonito (Permiano Inferior) na região de Taió, Santa Catarina, Brasil. Revista Brasileira de Paleontologia, 10:201-211.

Brongniart, A. 1828. Prodomus d'une Histoire des Végétaux Fossiles. Paris, VIII, 233 p.

Boureau, E. 1964. Traité de Paléobotanique: Sphenophyta. Paris, Ed. Masson et Cie, v. III, $554 \mathrm{p}$.

Cazzulo-Klepzig, M. \& Guerra-Sommer, M. 1983. O morfogênero Phyllotheca em sedimentitos da Formação Rio Bonito no Rio Grande do Sul. In: SIMPÓSIO SUL-BRASILEIRO DE GEOLOGIA, 1, 1983. Atas, Porto Alegre, SBG, 1:160-169.

Chachlov, V.A. 1964. The Upper Paleozoic flora of the north Siberia. Izdatel Tomsk University. Tomsk.

Cúneo, R.; Archangelsky, S. \& Wagner, R.W. 1993. Lower Permian Sphenophylls from Chubut, Argentina. Ameghiniana, 30:225-243.

DiMichele, W.A. \& Hook, R.W. 1992. Paleozoic Terrestrial Ecosystems. In: A.K. Behrensmeyer; J.D. Damuth; W.A. DiMichele; R. Potts; H.D. Sues, \& S.L. Wing (eds.) Terrestrial ecosystems through time, University of Chicago, p. 205-326.

Guerra-Sommer, M. \& Cazzulo-Klepzig, M.A. 1981. Tafoflora do Grupo Itararé no Rio Grande do Sul: sua importância bioestratigráfica no Gondwana Sul-Brasileiro. In: CONGRESSO LATINO-AMERICANO DE PALEONTOLOGIA, 2, 1981. Anais, Porto Alegre, SBP, 2:127-140.

Guerra-Sommer, M. \& Cazzulo-Klepzig, M.1993. Biostratigraphy of the Southern Brazilian Neopaleozoic Gondwana Sequence: a preliminary paleobotanical approach. In: INTERNATIONAL CONGRÈS DE LA STRATIGRAPHIE ET GÉOLOGIE DU CARBONIFÈRE ET PERMIEN, 12, 1991. Comptes Rendus, Buenos Aires, 2:61-72.
Guerra-Sommer, M.; Cazzulo-Klepzig, M. \& Marques-Toigo, M. 1985. Gondwanostachyaceae (Equisetopsida) no Godwana Sul-Brasileiro (Formação Rio Bonito) com mega e microflora associadas. Pesquisas, 22:64-73.

Iannuzzi, R. 2000. Presença do gênero Stephanophyllites em estratos eopermianos do Rio Grande do Sul, Brasil (Formação Rio Bonito, Bacia do Paraná). Revista Universidade Guarulhos, Geociências, 4:74-77.

Iannuzzi, R. 2010. The flora of Early Permian coal measures from the Paraná Basin in Brazil: a review. International Journal of Coal Geology, 83:229-247. doi:10.1016/j.coal.2010.05.009

Iannuzzi, R.; Marques-Toigo, M.; Scherer, C.M.S.; Caravaca, G.; Vieira, C.E.L. \& Pereira, L.S. 2003a. Reavaliação do fitobioestratigrafia da sequência Gondvânica Sul-Riograndense: estudo de caso do afloramento Morro do Papaléo (Bacia do Paraná, Permiano Inferior). In: ENCONTRO SOBREAESTRATIGRAFIADO RIO GRANDE DO SUL: ESCUDOS E BACIAS, 1, 2003. Resumos expandidos, Porto Alegre, ILEA/UFRGS, 1:182-185.

Iannuzzi, R.; Marques-Toigo, M.; Scherer, C.M.S.; Caravaca, G.; Vieira, C.E.L. \& Silva, L.P. 2003b. Phytobiostratigraphical revaluation of the Southern Brazilian Gondwana sequence (Paraná Basin, Lower Permian). In: INTERNATIONAL CONGRESS ON CARBONIFEROUS AND PERMIAN STRATIGRAPHY, 15, 2003. Abstracts, Utrecht University, p. 240-242.

Iannuzzi, R; Scherer, C.M.S.; Souza, P.A.; Holz, M.; Caravaca, G.; Adami-Rodrigues, K.; Tybusch, G.P.; Souza, J.M.; Smaniotto, L.P.; Fischer, T.V.; Silveira, A.S.; Likawka, R.; Boardman, D.R. \& Barboza, E.G. 2006. Afloramento Morro do Papaléo, Mariana Pimentel, RS. Registro ímpar da sucessão pós-glacial do Paleozóico da Bacia do Paraná. In: C. Schobbenhaus et al. (eds.) Sítios Geológicos e Paleontológicos do Brasil, vol. 2. $<$ http://www.unb.br/ig/sigep/sitio101/sitio101.pdf>

Iannuzzi, R.; Souza, P.A.; Scherer, C.M.S. \& Holz, M. 2007. Plantas fósseis na Bioestratigrafia dos depósitos permianos do Rio Grande do Sul. In: R. Iannuzzi \& J.C. Franz (eds.) 50 anos de Geologia, contribuições do Instituto de Geociências, Editora Comunicação \& Identidade, p. 41-57.

Iannuzzi, R.; Souza, P.A. \& Holz, M. 2010. Stratigraphic and paleofloristic record of the Lower Permian postglacial succession in the southern Brazilian Paraná Basin. In: LATE PALEOZOIC GLACIAL EVENTS AND POSTGLACIAL TRANSGRESSIONS IN GONDWANA, 2010. Special Paper, Denver, GSA, p. 113-132.

Lundqvist, G. 1919. Fossile Pflanzen der Glossopteris Flora aus Brasilien. Kunglia Svenska Vetenskapsakdemies Handlingar, 60:1-36.

Maheshwari, H.K. 1968. Studies in the Glossopteris Flora of India - 38. Remarks on Tryzygia speciosa noyle with reference to the Genus Sphenophyllum Koenig. The Paleobotanist, 16:283-287.

McLoughlin, S. 1992. Permian Sphenophytes from the Collies and Perth Basins, Western Austrália. Review of Palaeobotany and Palynology. 75:153-182. doi. org/10.1016/0034-6667(92)90015-9

Meyen, S.V. 1967. New data on the relationship between Angara and Gondwana Lata Paleozoic floras. In: INTERNATIONAL UNION OF GEOLOGICAL SCIENCES, SYMPOSIUM ON GONDWANA STRATIGRAPHY, 1, 1967. Proceedings, Buenos Aires, p. 144-152.

Meyen, S.V. 1971. Phyllotheca-like plants from the Upper Paleozoic flora of Angaraland. Palaeontographica, 133:1-33.

Meyen, S.V. 1987. Fundamentals of Paleobotany. New York, Chapman and Hall, 432 p. 
Millan, J.H. \& Dolianiti, E. 1977. Esfenófitas do Eogondwana de Cerquilho, São Paulo (Bacia do Paraná), Brasil. 1- Gênero Paracalamites. Anais da Academia Brasileira de Ciências, 49:469-477.

Millan, J.H. \& Dolianiti, E. 1979. Esfenófitas do Eogondwana de Cerquilho, São Paulo (Bacia do Paraná), Brasil. 3- Gênero Phyllotheca. Boletín de la Asociacion Latinoamericana de Paleobotanica y Palinologica, 6:1-4.

Millan, J.H. \& Dolianiti, E. 1980. Esfenófitas do Eogondwana de Cerquilho, São Paulo (Bacia do Paraná), Brasil. 2- Gênero Stephanophillites gen. nov. In: CONGRESO ARGENTINO DE PALEONTOLOGIA Y BIOESTRATIGRAFIA, 2/ CONGRESO LATINOAMERICANO DE PALEONTOLOGIA, 1, 1980. Actas, Buenos Aires, 4:113-127.

Neuburg, M.F. 1948. Upper Paleozoic flora of Kuznetsk basin. Moscow, Paleontology of USSR, 342 p.

Oliveira-Babinski, M.E.C.B. 1988. Equisetales eogondvânicas da "Tafoflora Irapuá", Formação Rio Bonito (Permiano Inferior) em Criciúma, SC, Bacia do Paraná, Brasil. Anais da Academia Brasileira de Ciências, 60:45-60.

Pant, D.D. \& Kidwai, P.F. 1968. On the structures of stems and leaves of Phyllotheca indica Bunburry, and its affinities. Paleontographica, Series B, 4-6:102-121.

Rasskazova, E.S. 1961. Chlenistosebipnye Verkhnego Paleozoia iz Tungusskogo Bass. NIIGA Spornik statei po Paleontogie $i$ biostrattigraphie, 23:35-74.

Read, C.B. 1941. Plantas Fósseis do Neo-Paleozoico do Paraná e Santa Catarina. Rio de Janeiro, Ministério da Agricultura, Divisão de Geologia e Mineralogia, 102 p. (Monografia 12).

Roesler, G.A.; Iannuzzi, R.; Boardman, D.R. \& Baroni, C.L. 2008. Uma nova espécie de Phyllotheca Brongniart (Townrow) no
Permiano Inferior da Bacia do Paraná, RS. Gaea, 4:14-23.

Rohn, R. \& Rösler, O. 1987. Relações entre a flora permiana do Gondvana e as floras das províncias setentrionais. In: CONGRESSO BRASILEIRO DE PALEONTOLOGIA, 10, 1987. Anais, Rio de Janeiro, 2:886-899.

Rohn, R. \& Rösler, O. 2000. Middle to Upper Permian phytostratigraphy of the Eastern Paraná Basin. Revista Universidade Guarulhos, Geociencias, 5:69-73.

Rohn, R. \& Lages, L.C. 2000. Lower Permian sphenopsids from Cerquilho, Northestern Paraná Basin, Brazil. Revue Paléobiologie, 19:359-379.

Rösler, O. 1974. Novas espécies de Sphenophyta na Formação Rio Bonito (Permiano) no Estado do Paraná. Boletim IG-USP, 5:17-28.

Schmalhausen, J.1879. Beitrage zue Jura-Flora Russlands. Academiae Imperialis Scientiarum St.-Petersbourg Mem., 27:1-96.

Townrow, J.A. 1955. On some species of Phyllotheca. Journal and Proceedings of the Royal Society of New South Wales, 83:39-63.

White, D. 1908. Fossil flora of the coal measures of Brazil. In: I.C. White (ed.) Comissão Estadual das Minas de Carvão de Pedra do Brazil, Relatório Final, p. 337-617.

Zalessky, M.D. 1918. Flore paleozoique de la sene d'Angara. Mémoire du Comité Géologique de Russie, 174:1-76.

Zampirolli, A.P.; Bernardes-de-Oliveira, M.E.C. \& Souza, P.A. 2000. Esfenopsída equisetaleana cf. Koretrophyllites sp., na tafoflora neocarbonífera do Subgrupo Itararé, Bacia do Paraná, no Município de Itapeva, SP, Brasil. Revista Universidade Guarulhos, Geociências, 4:96-101.

Received in August, 2011; accepted in April, 2012. 